\title{
Assessment of Common Perinatal Mental Disorders in a Selected District Hospital of the Eastern Province in Rwanda
}

\author{
Marie Providence Umuziga ${ }^{1}$, Oluyinka Adejumo ${ }^{2}$, Michael Hynie ${ }^{3}$ \\ ${ }^{1}$ University of Rwanda, College of Medicine and Health Sciences, Rwanda \\ ${ }^{2}$ University of the Western Cape, Community and Health Sciences, Rwanda \\ ${ }^{3}$ Department of Psychology, York University, Canada
}

\section{Background}

Common perinatal mental disorders (CPMDs) in women (depression \& anxiety) are recognized as a significant public health concern. In African countries, CPMDs are most prevalent. However, there is limited evidence in literature about CPMDs in Rwanda.

\section{Purpose}

To determine CPMDs in a selected district hospital of the Eastern Province of / Rwanda.

\section{Methods}

Descriptive quantitative cross-sectional survey was conducted with a sample of 165 mothers in perinatal period selected systematically. Ethical approval was obtained from University of the Western Cape of South Africa and the former Kigali Health Institute of Rwanda. The Zungu Self-rating Anxiety Scale (SAS) and Edinburgh Postnatal Depression Scale (EPDS) were used to collect data. SPSS version 21 was used for analysis.

\section{Results}

Most of the respondents (38.2\%) were aged 25-29 years; married (44.8\%); and unemployed (77\%). Thirty-seven percent of the respondents had perinatal anxiety (PNA) while $50.3 \%$ had perinatal depression (PND). Statistically significant relationships were found between PNA ( $\geq 45$ scores) and factors such as relationship with husband/partner $\left(\mathrm{c}^{2}{ }_{(2)}=12.045, \mathrm{p}=.002\right)$, husband/partner's behaviour $\left(\mathrm{c}^{2}{ }_{(8)}=16.401, \mathrm{p}=.037\right)$, number of children $\left(\mathrm{c}_{(8)}^{2}=16.017, \mathrm{p}=.042\right)$, planned pregnancy $\left(\mathrm{c}^{2}{ }_{(2)}=8.244, \mathrm{p}=.016\right)$, stressful events $\left(\mathrm{c}^{2}{ }_{(14)=} 55.035, \mathrm{p}=.000\right)$. Relationship with husband/partner was the only predictor of PNA (Odd ratio $=0.437$ ). With regard to PND ( $\geq 10$ scores), statistically significant relationships were found between factors such as marital status $\left(\mathrm{c}^{2}{ }_{(3)}=\right.$

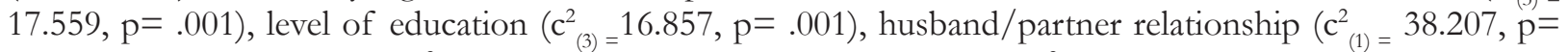
$.000)$, husbands' behaviour $\left(\mathrm{c}^{2}{ }_{(4)}=43.242, \mathrm{p}=.000\right)$, number of children $\left(\mathrm{c}^{2}{ }_{(4)}=18.554, \mathrm{p}=.001\right)$, planned pregnancy $\left(\mathrm{c}^{2}{ }_{(1)}=17.773, \mathrm{p}=.000\right)$, personal stressful events $\left(\mathrm{c}^{2}(7)=30.232, \mathrm{p}=.000\right)$. Age was the strongest determinants of PND (Odd ratio: 131.973).

\section{Conclusion}

CPMDs are prevalent. Poor relationship with husband and young age were found to be the strongest determinants of CPMDs.

Key words: ante-postnatal depression, ante-postnatal anxiety, Rwanda 